\title{
Base Performances of Cement-Stabilized Magnesium Slag-Aeolian Sand Mixture
}

\author{
Hongjun JING ${ }^{1,2}$, Jiahao ZHANG ${ }^{1,2 *}$, Meng GAO ${ }^{1,2}$, Qian $\mathrm{LIU}^{1,2}$ and \\ Emilia WO£OWIEC-KORECKA ${ }^{3}$
}

\begin{abstract}
Authors' affiliations and addresses:
${ }^{1}$ School of Architectural and Civil Engineering,

Xi'an university of science and technology, No.58

Yanta Road, Xi'an City, Shaanxi Province, China

${ }^{2}$ Road Engineering Research Center of Xi'an

University of Science and Technology, No.58

Yanta Road, Xi'an City, Shaanxi Province, China

e-mail: jinghongjun@xust.edu.cn

e-mail: 1504050416@stu.xust.edu.cn

e-mail: 19204053013@stu.xust.edu.cn

e-mail: $19204053022 @$ stu.xust.edu.cn
\end{abstract}

${ }^{3}$ Institute of Materials Science and Engineering, Lodz University of Technology, Stefanowskiego 1/15, Lodz, Poland, emilia.wolowiec-

korecka@p.lodz.pl

\section{*Correspondence:}

Jiahao Zhang, College of Architectural and Civil Engineering, Xi'an university of science and technology, No.58 Yanta Road, Xi'an City,

Shaanxi Province, China

e-mail: 1504050416@stu.xust.edu.cn

How to cite this article:

Jing, H., Zhang, J., Gao, M., Liu, Q. and

Wo£owiec-Korecka, E. (2021). Base

Performances of Cement-Stabilized Magnesium

Slag-Aeolian Sand Mixture. Acta Montanistica

Slovaca, Volume 26 (3), 427-443

DOI:

https://doi.org/10.46544/AMS.v26i3.04

\begin{abstract}
Many problems are encountered in the disposal of abundant magnesium slags, remarkable ecological environmental damages by stacking and landfill of magnesium slag, poor properties of soil-rock materials, and high pavement cost in Yulin City, China. This study focused on the combined use of feasibility of magnesium slag-Aeolian sand in pavement base to address the problems above. The physical and chemical properties of magnesium slag and Aeolian sand were obtained through tests on the basic properties of raw materials. Different mixing ratios of magnesium slag and Aeolian sand and cement content were designed. Moreover, a comparative study on the compaction characteristics and water stability, as well as unconfined compressive strength, splitting strength, and compressive modulus of resilience of five groups of cement-stabilized magnesium slag-Aeolian sand mixtures in different periods, was conducted through a series of systematic laboratory tests. The impact degrees of different factors on compressive strength were calculated by the grey relational analysis method. Finally, the test section was paved by combining laboratory test results. Research results demonstrate that the active matter content is high, and the crushing value of magnesium slag is also high. The optimal water content of the mixture increases with the magnesium slag content, while the maximum dry density decreases. The mixture's unconfined compressive strength, splitting strength, and compressive modulus of resilience in different curing periods all increased with the magnesium slag and cement contents. Moreover, magnesium slag content has minimal influence on splitting strength compared with unconfined compressive strength. Among all factors, cement content provides the most influence on the compressive strength, followed by water content, magnesium slag content, and curing period successively. The $7 \mathrm{~d}$ compressive strength of mixtures with different mixing ratios meets the strength requirements of the base and subbase of different highway grades, and all mixtures show good water stability. The test road also achieves good performance. These findings prove that using cement-stabilized magnesium slagAeolian sand mixture as the pavement base and subbase materials is feasible. The magnesium slag content should be higher than $45 \%$ under $5 \%$ cement content to meet the strength requirements base. This study can provide references to the applications of magnesium slag and Aeolian sand in semi-rigid base materials.
\end{abstract}

\section{Keywords}

Road engineering, cement-stabilized magnesium slag-Aeolian sand, semi-rigid base, mechanical properties, grey relational degree 


\section{Introduction}

Metal magnesium has been attracting increasing attention for its rich reserves and excellent performances since the $21^{\text {st }}$ century (Kumar, Kumae \& Mukhopadhyay, 2018) and has been widely applied in various fields. Magnesium also possesses promising development prospects in industries. In 2020, the original magnesium output in China was 907,000 tons, ranking top in the world. In particular, Yulin City, China, is an important magnesium production base around the country. Nearly 50 magnesium and magnesium processing enterprises are found in Yulin City, and the raw magnesium output accounts for approximately 50\% of the total output in China and $40 \%$ of the global output. However, the magnesium industry is facing some general problems, such as a small production scale, high pollution, high energy consumption, and low technological innovation capability. This industry will produce 5-6 t of magnesium slags for every $1 \mathrm{t}$ of magnesium output. Thus far, several million tons of magnesium slags cannot be disposed of in China. The output of magnesium slags will continue to increase with the annual growth of magnesium consumption demands. Magnesium slags are pulverized in the process of natural cooling after discharging, introducing mobility and adhesiveness. At present, many magnesium plants have no standard magnesium slag disposal methods and only randomly stack or landfill the discharged magnesium slags as wastes (Shen \& Forssberg, 2003), which occupy considerable land resources. Magnesium slag belongs to metallurgic wastes containing heavy metal elements. These elements will penetrate rivers and soils with rainwater, thus causing serious impacts on crops and surrounding environments (Djokic, Minic \& Kamberovic, 2012). Scholars worldwide have made numerous explorations in recycling magnesium slags due to urgent demands for resource use and environmental protection (Osmani, Shabani \& Ilazi, 2020; Martinez-Sentana, Valero-Verdu \& SenabreBlanes, 2020), but most of these explorations are still in the research stage. Tremendous amounts of magnesium slags have not been used effectively. Hence, developing a new idea for the use of magnesium slags has become a trend.

Yulin City, China, which is in the northernmost region of Shaanxi Province, is in the transition zone between Loess Plateau and Inner Mongolian Plateau. The desert area occupies 36.7\% of the city's total area and has rich mineral resources (Zhai et al., 2020). Hence, Yulin City possesses an extremely high development strategic position. Developing the highway construction of this region not only promotes balanced economic development in the city (Solonenko, 2019) but also perfects the transportation network with external mineral resources, supports economic development in other regions in China, and accelerates national economic development and modernized construction. By contrast, highway construction cannot be performed without abundant pavement materials. The selection and use of materials not only reflect the normal development of highway performances but also plays a decisive role in highway construction cost. Soil and stone materials in Yulin City, China, have poor properties. Traditionally, natural soil and stone materials from other provinces are the major materials used to construct the pavement base. However, the exploitation of soil and stone resources has remarkably high environmental, exploitation, and transportation costs (Shang, 2019), which is inconsistent with the green development philosophy of low-carbon environmental protection and the use of local materials. Compared with traditional soil and stone materials, Aeolian sand in Yulin City has rich reserves and low cost, thus becoming a new substitution of traditional materials in pavement base. The Research on Comprehensive Use of Aeolian Sand in Road Construction Technology was implemented in Yulin City in 2015. Subsequently, Aeolian sand was successfully used in the sealing and base layers of pavements, which has achieved good economic and ecological benefits.

Magnesium slags, which are recyclable resources, propose an urgent need for recycling to address the above problems. Aeolian sand has rich reserves and low cost, which agrees with the current status of pavement material shortage and high pavement cost. Hence, magnesium slag and Aeolian sand were combined and used in the construction of pavement base to relieve environmental pressure caused by magnesium slags to the maximum extent, solve the current stone shortage, and save material transport cost and time. This study can provide references to the applications of similar industrial slags in pavement and road construction in desert areas. Such a combination also has promising application prospects. Promoting economic construction, sustainable traffic development, and environmental protection in regions with rich mineral resources and desert resources in China is crucial. 


\section{State of the Art}

After compaction, Aeolian sand can show a relatively high modulus of compression, quick compression, small compressive deformation, small post-construction settlement, and low creeping characteristics (Zhang et al., 2007). Hence, Aeolian sand is a type of ideal pavement construction material. Scholars have used Aeolian sand as pavement filling and conducted numerous explorations on the application of Aeolian sand in pavement base after solidification. Ge, Ge and Yang (2005) indicated that Aeolian sand can be used as subgrade materials in filling salinized soil frothing and unsanded regions through experimental studies and analysis. They reported that Aeolian sand can develop economic and social benefits as long as using effective reinforcement and compaction. Shalabi et al. (2019) aimed to increase the strength, California bearing ratio (CBR), and rigidity by using cement processed Aeolian sand. Lopez et al. (2017) improved the compaction characteristics and CBR of Aeolian sand through cement stabilization and found a significant linear relation between them. They also found that high cement content can considerably improve the Aeolian sand. Song and Li (2020) conducted a comprehensive laboratory test and detection of the testing section. They found that the performances of the cement-stabilized graded crushed stone mixture were worsened with the increase in Aeolian sand content. Thus, replacing fine aggregates with few Aeolian sand in the cement-stabilized macadam base was feasible. Guo, Zhang and Du (2017) studied the shear strength of cement-stabilized Aeolian sand into the highway base and disclosed influencing factors and action mechanisms of cement content on the shear strength of Aeolian sand base. Overall, the cement-stabilized macadam-Aeolian sand base has good stability and mechanical properties. However, only a few fine aggregates replaced by Aeolian sand cannot realize the goal of abundant use, and cement-stabilized Aeolian sand is only applicable to the subgrade sealing layer and pavement subbase. Trials in the mixing of Aeolian sand and other materials in road construction are currently limited. As a type of economic recycling resource with stable performance, studying the large-scale applications of Aeolian sand in pavement base and expanding the pavement application scope of Aeolian sand is necessary.

Many scholars have used industrial slags in the construction of pavement bases to solve the environmental pollution caused by the failure of industrial slag disposal. Some of them (Maghool et al., 2017; Li et al., 2017; Karatag, Firat \& Isik, 2020) studied the replacement of macadam by steel slag into the cement-stabilized base. They found that steel slags were beneficial to improve drying and temperature shrinkage characteristics of semi-rigid base materials and were suitable as pavement base materials due to their good engineering characteristics. Zhang et al. (2007) and Mao (2018) studied the strength characteristics and temperature shrinkage of coal gangue and Zinc slag when used in cementstabilized base and proved their applicability to pavement base in cold regions. Zhang and Ren (2018) investigated the strength and damage characteristics of cement-stabilized slag macadam, gained the optimal mixing ratio of the cement-stabilized slag macadam base, and constructed the constitutive relation under unconfined compression conditions. Jiang (2018) studied the strength mechanism difference between iron tailing sand of inorganic binders and ordinary sand. Moreover, they conducted the optimal design and application of iron tailing sand base and proposed technological standards to use iron tailing sand as the base materials.

The above studies have achieved successful experiences of using industrial slags in pavement bases. At the beginning of the 1980s, China used magnesium slag into the pavement base and proved that magnesium slag was an ideal pavement base material. A new way was proposed to construct black pavement bases in sand-free regions based on similar experiences. Therefore, the lime-flyash-stabilized magnesium slags were used to construct a pavement base, which achieved significant social and economic benefits. However, the lime-flyash magnesium slag base could not adapt to the currently large traffic flows and loads. The abundant stacking of magnesium slag has become a remarkable constraint against sustainable industrial development due to the extensive applications of magnesium and magnesium alloy since the $21^{\text {st }}$ century. Scholars have been devoted to studying the recycling of magnesium slags. However, these studies mainly concentrate on fields of magnesium slag calcined cement clinker, modified asphalt and as binding materials. For example, Zhao, Han and Wang (2017) designed the mix proportion scheme of magnesium and manganese slags to prepare the sulfate aluminium cement clinker. The mixing ratio of the two slags could reach as high as $21 \%$. Moreover, they found that mixing a certain amount of gypsum can prepare early-strength and fast-hardening cement. Du et al. (2010) studied asphalt modification by using magnesium slag as the mineral powder 
through an orthogonal test and found that replacing less than $60 \%$ of limestone mine with magnesium slag is feasible, which could improve the cohesiveness of asphalt. Xiao et al. (2011) chose the method of "mixing and then grinding" and developed magnesium slag binding materials by adding three alkaliactivators. They further prepared low-mass and high-strength excellent wall materials by combining the prepared magnesium slag binding materials with EPS ultralight aggregate and other additives. Liu et al. (2020) proposed a new idea of preparing binding materials by using magnesium slag and high-calcium flyash and then combining them with Aeolian sand to be the backfilling material of mining mountains. They found that adding flyash can motivate the continuous pozzolanic reaction of magnesium slag and increase the feasibility of green backfilling in mining mountains. Based on similar composition characteristics of magnesium slag and Portland cement clinker, some scholars (Liu, Ma \& Zheng, 2019; Ji et al., 2017) mixed the magnesium slag and traditional binding materials to study and prove that adding magnesium slag can effectively increase the mechanical properties of materials. The above studies indicate that many scholars continuously deepen their understanding of magnesium slag with technological progress and process improvement. The application fields and methods of magnesium slag are continuously enriching. However, some problems, including excessively small use volume, high recycling cost, and underuse of magnesium slag activity, remain. Moreover, studies that use magnesium slag as pavement base materials are relatively few. Additional scientific pavement bases of magnesium slags must be explored to utilize magnesium slag resources completely.

Magnesium slag and Aeolian sand were used as the research objects considering the experiences and shortcomings of existing studies, and their comprehensive use in a semi-rigid base was studied. Therefore, mixtures with different mixing ratios between cement content and magnesium slag-Aeolian sand were set on the basis of the analysis of basic properties of magnesium slag and Aeolian sand to study the performances of cement-stabilized magnesium slag-Aeolian sand mixture, including unconfined compressive strength, splitting strength, compressive modulus of resilience, and water stability. The impact degrees of different influencing factors on unconfined compressive strength were also compared. The feasibility of using magnesium slag-Aeolian sand as the cement-stabilized base was evaluated by paving a test section. This study aimed to expand the application scope of magnesium slag and Aeolian sands and established foundations for the large-scale use of magnesium slags and Aeolian sands in pavement base.

The remainder of this study is organized as follows. Section 3 introduces the material properties and testing program. Section 4 analyses and discusses the results of the tests. Section 5 proves the performance of the testing section. Section 6 summarises the conclusions of this work.

\section{Materials and Methodology}

\section{Material Properties}

Cement. This study used the P.O $42.5 \mathrm{H}$ cement produced by China Shaanxi Beiyuan Group Cement Co. Ltd. The properties of this cement conform to the requirements of the Common Portland Cement (GB 175-2007). Tab. 1 shows the specific performance indexes.

Tab. 1. Test results of cement performances

\begin{tabular}{cccccccc}
\hline Test item & $\begin{array}{c}\text { Specific surface } \\
\text { area }\left[\mathrm{m}^{2} / \mathrm{kg}\right]\end{array}$ & $\begin{array}{c}\text { Initial } \\
\text { setting time } \\
{[\mathrm{min}]}\end{array}$ & $\begin{array}{c}\text { Final setting } \\
\text { time [min] }\end{array}$ & Stability & $\begin{array}{c}\text { 3D rupture } \\
\text { strength [MPa] }\end{array}$ & $\begin{array}{c}\text { 3D compressive } \\
\text { strength [MPa] }\end{array}$ & $\begin{array}{c}\text { Loss on ignition } \\
{[\%]}\end{array}$ \\
\hline Results & 345 & 391 & 456 & Qualified & 5.0 & 27.4 & 1.92 \\
\hline
\end{tabular}

Magnesium Slag. The used magnesium slag used the granular optimized magnesium slag produced by Yulin Jingjie Dongfeng Magnesium Company, China (Fig. 1). This slag includes the optimized coarse magnesium slag $(>4.75 \mathrm{~mm})$ and fine slag $(<4.75 \mathrm{~mm})$. The production principle is as follows: an optimizing agent was added into the magnesium smelting process based on the Pidgeon process, which can effectively stabilize $\beta-C_{2} S$ in magnesium slag and stop its transformation into $\gamma-C_{2} S$ in the cooling process, thus avoiding magnesium slag pulverization. Hence, most magnesium slags can still maintain the granular shape after natural cooling. 


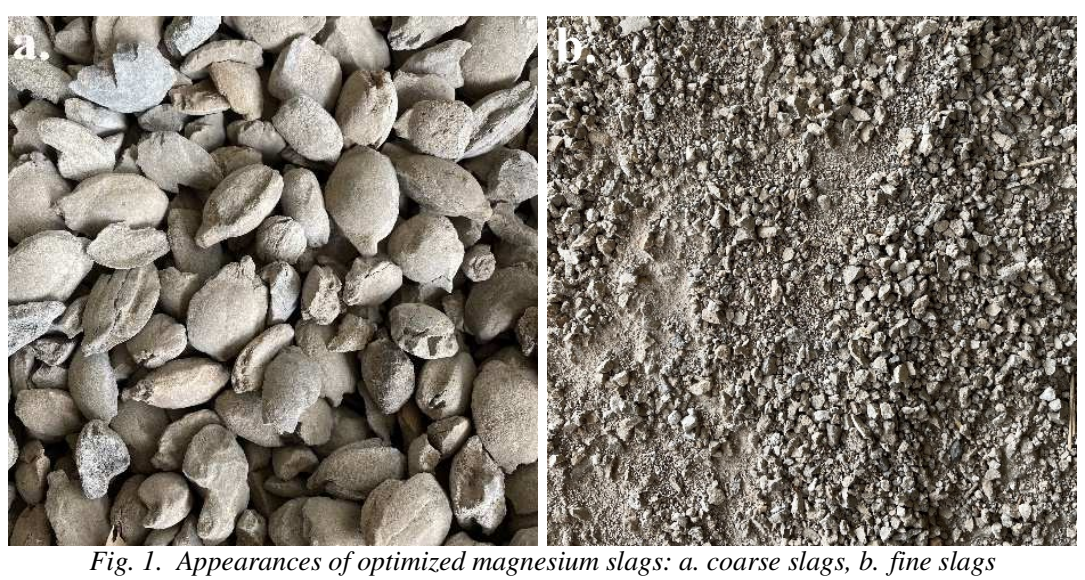

Magnesium slags were screened by the inquartation method to understand particle size distribution after magnesium slag delivery and guide the mixture composition design in the late stage. Tab. 2 shows the screening results. Extensive grain size distributions of magnesium slags were found, and the maximum particle size exceeded $19 \mathrm{~mm}$. In the laboratory test, magnesium slags were divided into the following four grades: 1\# (19-31.5 mm), 2\# (9.5-19 mm), 3\# (4.75-9.5 mm), and 4\# (0-4.75 mm). The proportions of each grade were fixed and used after mixing.

Tab. 2. Particle size distribution of the optimized magnesium slag

\begin{tabular}{cccccccc}
\hline Mesh size [mm] & 31.5 & 19 & 9.5 & 4.75 & 2.36 & 0.6 & 0.075 \\
\hline Passing mass percentage [\%] & 100 & 79.1 & 46.6 & 27.0 & 19.6 & 12.3 & 3.6 \\
\hline
\end{tabular}

A basic physical performance test of coarse and fine slags was performed following the Test Methods of Aggregate for Highway Engineering (JTG E42-2005). Tabs. 3 and 4 list the results. Compared with the technological requirements in Technical Guidelines for Construction of Highway Roadbases (JTG/T F20-2015) on cement-stabilized materials, the crushing value and water absorption of magnesium slags are relatively high, and the self-strength was relatively low.

Tab. 3. Physical properties of coarse magnesium slags

\begin{tabular}{|c|c|c|c|c|}
\hline $\begin{array}{c}\text { Apparent density } \\
{\left[\mathrm{g} / \mathrm{cm}^{3}\right]}\end{array}$ & $\begin{array}{c}\text { Water absorption } \\
{[\%]} \\
\end{array}$ & $\begin{array}{c}\text { Flat and elongated particle in aggregate } \\
{[\%]}\end{array}$ & $\begin{array}{c}\text { Crushing value } \\
{[\%]}\end{array}$ & $\begin{array}{c}\text { Silt content } \\
{[\%]} \\
\end{array}$ \\
\hline 2.063 & 11.58 & 23.6 & 36.5 & 0.3 \\
\hline
\end{tabular}

Tab. 4. Physical properties of fine magnesium slags

\begin{tabular}{cccccc}
\hline Apparent density $\left[\mathrm{g} / \mathrm{cm}^{3}\right]$ & Water absorption [\%] & Loss on ignition [\%] & Liquid limit [\%] & Plastic limit [\%] & Plasticity index \\
\hline 2.282 & 11.74 & 6.67 & 38 & 23 & 15.0 \\
\hline
\end{tabular}

A chemical analysis of magnesium slags revealed that $\beta-\mathrm{C}_{2} \mathrm{~S}$ is the major mineral phase of magnesium slags, and the major chemical compositions were $51 \% \mathrm{CaO}, 30.5 \% \mathrm{SiO}_{2}, 6.3 \% \mathrm{MgO}, 5.64 \%$ $\mathrm{Fe}_{2} \mathrm{O}_{3}$, and $5.37 \% \mathrm{Al}_{2} \mathrm{O}_{3}$.

Aeolian Sand. Aeolian sand samples were collected from Guojiawan Town, Fugu County, Yulin City, China. Tab. 5 shows the screening results. The fineness modulus was $M_{x}=1.375$, which ranges between 0.7-1.5, indicating that the Aeolian sand was ultrafine. The coefficient of nonuniform Aeolian sand was $\mathrm{C}_{\mathrm{u}}=3.3<5$, indicating the extensive particle size range. Hence, Aeolian sand is easily compacted. The coefficient of curvature was $\mathrm{C}_{\mathrm{c}}=1.1$, which was between 1 and 3 , indicating the good continuity of particle size distribution of Aeolian sand. With comprehensive considerations to curvature and nonuniform coefficients, Aeolian sand has poor gradation. 
Tab. 5. Screening results of Aeolian sand

\begin{tabular}{ccccccc}
\hline Mesh size [mm] & 1.18 & 0.6 & 0.3 & 0.15 & 0.075 & $0-0.075$ \\
\hline Grader retained percentage [\%] & 0 & 5.5 & 43.0 & 35.0 & 12.1 & 4.4 \\
Accumulated retained percentage [\%] & 0 & 5.5 & 48.5 & 83.5 & 95.6 & 100 \\
Passing mass percentage [\%] & 100 & 94.5 & 51.5 & 16.5 & 4.4 & - \\
\hline
\end{tabular}

The physical properties of Aeolian sand were tested as shown in Tab. 6.

\begin{tabular}{|c|c|c|c|c|c|c|}
\hline $\begin{array}{c}\text { Apparent density } \\
{\left[\mathrm{g} / \mathrm{cm}^{3}\right]}\end{array}$ & $\begin{array}{c}\text { Accumulated density } \\
{\left[\mathrm{g} / \mathrm{cm}^{3}\right]}\end{array}$ & $\begin{array}{c}\text { Water absorption } \\
{[\%]} \\
\end{array}$ & $\begin{array}{c}\text { Silt content } \\
{[\%]}\end{array}$ & $\begin{array}{c}\text { Liquid limit } \\
{[\%]}\end{array}$ & $\begin{array}{c}\text { Plastic limit } \\
{[\%]}\end{array}$ & $\begin{array}{c}\text { Plasticity } \\
\text { index }\end{array}$ \\
\hline 2.551 & 1.548 & 0.96 & 2.39 & 21.3 & 13.6 & 7.7 \\
\hline
\end{tabular}

\section{Methodology}

Composition Design of Mixtures. The used Aeolian sand has poor gradation and extensive particle size distribution range and is easily compacted. Therefore, Aeolian sand is used as the fine aggregate in the mixture to change the engineering characteristics of poor gradation. Magnesium slag has a high crushing value. In the compaction test, some coarse slags were crushed to different degrees and were mixed with Aeolian sand to ensure structural stability. On the one hand, magnesium slag gradation was continuous, and the size of Aeolian sand concentration was within $0.075-0.6 \mathrm{~mm}$. On the other hand, the inorganic binder of magnesium slag mixed with Aeolian sand has remarkably uncertain performances. In the large-scale use of magnesium slag and Aeolian sand, many problems are encountered in the direct use of relevant technological norms for ordinary materials. Hence, designing an appropriate mixing ratio and gradation is necessary.

Based on the above problems, this study explored the feasibility of using magnesium slag-Aeolian sand mixture in the pavement base to realize the large-scale use of magnesium slag and Aeolian sand in engineering constructions. Cement content was set to 3\%, 5\%, and 7\% in this study, and the overall blending method (the gradation of magnesium slag was adjusted, and then Aeolian sand was mixed in accordance with certain proportions) was applied. The magnesium slag content (mass fraction) was set to $40 \%, 60 \%$, and $80 \%$, while Aeolian sand content was adjusted accordingly. Five testing groups were also set. Tabs. 7 and 8 respectively list the specific mixing ratios and mixture gradation under different mixing ratios. The coarse aggregate content in the mixture increases at equal proportions with the magnesium slag content. Hence, given the overall blending, magnesium slag content was used as the comprehensive parameter of magnesium slag content and mixture gradation in the following studies and analyses in this study.

Tab. 7. Mixing ratios of cement-stabilized magnesium slag-Aeolian sand mixtures

\begin{tabular}{cccc}
\hline Group No. & Cement content [\%] & Magnesium slag content [\%] & Aeolian sand content [\%] \\
\hline 3-B & 3 & 60 & 40 \\
5-A & 5 & 40 & 60 \\
5-B & 5 & 60 & 40 \\
5-C & 5 & 80 & 20 \\
7-B & 7 & 60 & 40 \\
\hline
\end{tabular}

Tab. 8. Gradation of different groups of cement-stabilized magnesium slag-Aeolian sand

\begin{tabular}{cccccccc}
\hline Magnesium slag-Aeolian sand mixing ratio & \multicolumn{7}{c}{ Passing rate under different mesh sizes [\%] } \\
& 31.5 & 19 & 9.5 & 4.75 & 2.36 & 0.6 & 0.075 \\
\hline Magnesium slag: Aeolian sand = 40:60 & 100 & 91.6 & 78.6 & 70.8 & 67.8 & 61.6 & 4.1 \\
\hline Magnesium slag: Aeolian sand =60:40 & 100 & 87.5 & 68.0 & 55.2 & 51.8 & 45.2 & 4.0 \\
\hline Magnesium slag: Aeolian sand = 80:20 & 100 & 83.3 & 57.3 & 40.6 & 35.7 & 28.8 & 3.8 \\
\hline
\end{tabular}

Specimen Preparation. Cylinder specimens, which were both $150 \mathrm{~mm}$ in diameter and height, were prepared in this laboratory test according to the granularity of materials. The following compressive 
strength, splitting strength, compressive modulus of resilience, and water stability tests were then conducted. The die-filling mass of workpieces was calculated in accordance with the maximum dry density and optimal water content, which were tested in the compaction test. Meanwhile, magnesium slag and Aeolian sand were prepared into mixed aggregate according to preset proportions and the diefilling mass. The preset volume of water was then added to soak the material for $4 \mathrm{~h}$. Subsequently, the reserved cement was added and mixed uniformly. Finally, the die was filled in the three layers. The die was compacted in this test into the mould through the static compaction method, and the compaction degree was $98 \%$. Specimens were cured for $3 \mathrm{~h}$ after specimen moulding and then de-moulded. These specimens were later placed in the standard curing room until the appointed curing period was reached. Subsequently, follow-up tests were conducted.

Test Method. The compact, unconfined compressive strength, splitting strength, and compressive modulus of resilience tests all strictly observed the Test Methods of Materials Stabilized with Inorganic Binders for Highway Engineering (JTG E51-2009). Specimen curing conformed to regulations in T 0845-2009 and was performed in the standard environment of $(20 \pm 2){ }^{\circ} \mathrm{C}$ temperature and $95 \%$ humidity. The compaction test was performed in accordance with the $\mathrm{C}$ method in $\mathrm{T}$ 0804-1994. The unconfined compressive and splitting strength tests were respectively performed following T 0805-1994 and $\mathrm{T}$ 0806-1994, and the curing periods were set at 3, 7, 28, and $90 \mathrm{~d}$ and 7, 28, 60, and $90 \mathrm{~d}$. The compressive modulus of resilience test was conducted in accordance with T 0807-1994, and the curing period was set at 7, 28, and $90 \mathrm{~d}$.

The ratio between unconfined and immersed compressive strengths was used to evaluate the water stability of the mixture. The external environment was simulated in this study. Each mixing ratio set two groups. The first group was the control group, in which specimens were immersed in water for $24 \mathrm{~h}$ after standard curing for $27 \mathrm{~d}$, and then the unconfined compressive strength was tested. In the second group, specimens were immersed for $7 \mathrm{~d}$ after standard curing for $27 \mathrm{~d}$, and then the unconfined compressive strength was tested. The results of the first and second groups were compared, and the strength variation ratio was calculated to evaluate the water stability of the mixture.

Gray Relational Analysis. Gray relational analysis (GRA) determines the difference and similarity among different sequences through the curves formed by the reference and comparison sequences (Mondal \& Pramanik, 2015). The relational degree reflects the closeness of comparison factors to the reference factor. The comparison factor, which influences the reference factor of the system, can mostly be found by calculating the relational degree. The comparison factor also has the highest association to the reference factor of the system. GRA does not need numerous samples and typical data distribution and usually has simple calculations. The specific calculation steps are introduced as follows (Balamurugan, 2020).

- Determine one reference sequence $X_{0}$.

$$
X_{0}=\left\{x_{0}(1), x_{0}(2), x_{0}(3), \cdots, x_{0}(n)\right\}
$$

- A total of m comparison sequences $X_{i}$ were involved.

$$
X_{i}=\left\{x_{0}(1), x_{0}(2), x_{0}(3), \cdots, x_{0}(n)\right\},(i=1,2,3, \cdots, m) .
$$

- Dimensionless data processing. Sequences with different units or initial values must be processed first to make them dimensionless, thus eliminating the effects of different dimensions of indexes. Herein, data processing adopted the "initialization" method. Therefore, the initial value of different sequences is as follows.

$$
Y_{i}=\left\{y_{i}(1), y_{i}(2), \cdots, y_{i}(n)\right\}=\left\{\frac{x_{i}(1)}{x_{i}(1)}, \frac{x_{i}(2)}{x_{i}(1)}, \cdots, \frac{x_{i}(n)}{x_{i}(1)}\right\},(i=1,2, \cdots, m)
$$

- Calculate the difference sequence $\Delta_{i}$.

$$
\Delta_{i}(k)=\left|y_{0}(k)-y_{i}(k)\right|,(i=1,2,3, \cdots, m ; k=1,2,3, \cdots, n),
$$




$$
\Delta_{i}=\left\{\Delta_{1}(1), \Delta_{2}(2), \cdots, \Delta_{i}(n)\right\},(i=1,2,3, \cdots, m) .
$$

- Calculate the relational coefficient $\xi_{i}(k)$.

$$
\xi_{i}(k)=\frac{\min _{i} \min _{k} \Delta_{i}(k)+\rho_{\max _{i}} \max _{k} \Delta_{i}(k)}{\Delta_{i}(k)+\rho_{i} \max _{i} \max _{k} \Delta_{i}(k)},(i=1,2,3, \cdots, m ; k=1,2,3, \cdots, n),
$$

where $\operatorname{minmin}_{i} \Delta_{i}(k)$ and $\max _{i} \max _{k} \Delta_{i}(k)$ are the minimum and maximum differences between two poles, respectively, and $\rho$ is the resolution coefficient, which is usually set to 0.5 .

- Calculate the relational degree. For the convenience of comparison, the mean relational coefficient between an index and the corresponding element of reference sequences was calculated for each comparison sequence, which is called a relational degree.

$$
\gamma_{i}=\frac{1}{n} \sum_{k=1}^{n} \xi_{i}(k),(i=1,2,3, \cdots, m ; k=1,2,3, \cdots, n)
$$

\section{Results and Discussion}

\section{Compaction Characteristics}

The heavy compaction method was adopted in the compaction test according to the regulations of compaction tests through which the maximum dry density and the optimal water content of different mixtures. Tab. 9 shows the results.

\begin{tabular}{ccc}
\multicolumn{3}{c}{ Tab. 9. Maximum dry density and optimal water content of mixtures } \\
\hline Mixture group & Maximum dry density $\left[\mathrm{g} / \mathrm{cm}^{3}\right]$ & Optimal water content [\%] \\
\hline 3-B & 1.914 & 9.5 \\
5-A & 2.077 & 9.9 \\
5-B & 1.968 & 10.4 \\
5-C & 1.828 & 11.1 \\
7-B & 2.008 & 10.6 \\
\hline
\end{tabular}

Tab. 9 shows that the magnesium slag content increases from $40 \%$ to $80 \%$, and the optimal water content of the mixture increases from $9.9 \%$ to $11.1 \%$ due to the high water absorption of magnesium slag. The maximum dry density of mixtures continuously decreases by approximately $12 \%$ from 2.077 $\mathrm{g} / \mathrm{cm}^{3}$ to $1.828 \mathrm{~g} / \mathrm{cm}^{3}$. Such a decrease is mainly due to the porous magnesium slag and its smaller density than that of Aeolian sand.

The study points out that with increasing lime sludge contents, the optimum moisture content increased due to the adsorption of water by lime sludge (Phanikumar \& Raju, 2020). The increase in cement content requires additional water for cement hydration. Moreover, cement has a small particle size, and increasing cement content can produce additional hydration products and decrease aggregate pores. Therefore, the optimal water content and maximum dry density of mixtures continuously increase with the cement content.

\section{Unconfined Compressive Strength}

Fig. 2 shows the test results of unconfined compressive strength of mixtures in different curing periods under $5 \%$ cement content and different magnesium slag contents, while those under $60 \%$ magnesium slag content and different cement contents are presented in Fig. 3. The relationship between compressive strength and curing period was fit to reflect the variation laws of unconfined compressive strength $\left(R_{t}\right)$ of the mixture with the increase in curing period $(t)$ intuitively. The fitting result models are shown in Figs. 2 and 3. 


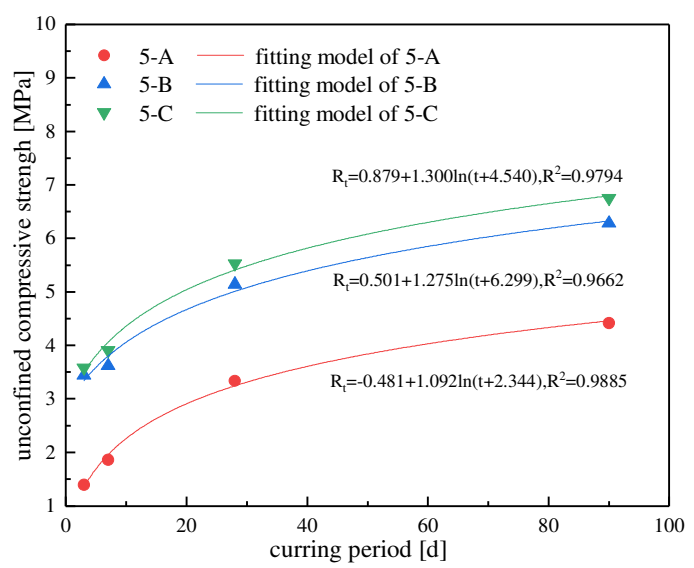

Fig. 2. Variation trend of unconfined compressive strength of the mixtures with magnesium slag content

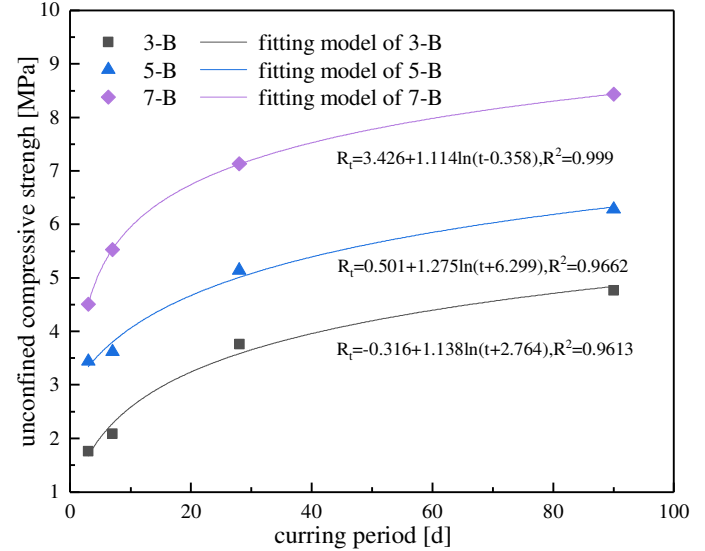

Fig. 3. Variation trend of unconfined compressive strength of mixtures with cement content

Figs. 2 and 3 show good logarithmic curve relations between unconfined compressive strength of different specimen groups and curing period. In the early curing period, strength quickly increased with the curing period. The unconfined compressive strength was increased by $17.9 \%$ on average from $3 \mathrm{~d}$ to $7 \mathrm{~d}$ of the curing period and by $54.4 \%$ from $7 \mathrm{~d}$ to $28 \mathrm{~d}$ due to the following reasons. As the results of the related study, the increase of magnesium slag content can significantly enhance the compressive strength of the mixes, which is consistent with the present study (Amini \& Ghasemi, 2019). Magnesium slag contains numerous hydration active minerals, such as $\beta-\mathrm{C}_{2} \mathrm{~S}, \mathrm{f}-\mathrm{CaO}$, and $\mathrm{MgO}$, and has similar hydration activity with cement (Liu et al., 2020). Therefore, magnesium slag can react with water to produce abundant C-S-H gels and calcium hydroxide. Moreover, active oxides of $\mathrm{SiO}_{2}$ in magnesium slag can facilitate the pozzolanic reaction with calcium hydroxide to strengthen the binding among particles in the mixture. Cement hydration is the main reason for the formation of base strength, which leads to the further formation of calcium silicate hydrate (Barišić et al., 2013). Meanwhile, the generation of $\mathrm{Ca}(\mathrm{OH})_{2}$ is accompanied by a volcanic ash reaction. The hydration and pozzolanic reactions occupy the dominant position when magnesium slag, cement, and water are mixed with increasing early strength significantly. However, the growth rate of compressive strength after $28 \mathrm{~d}$ significantly dropped. This reduction is due to the close relationship of compressive strength of cementstabilized mixture with cohesive force and aggregate strength (Singh, Tripathy \& Ranjith, 2008). Cement hydration was gradually completed in the late curing period, and the bonding force between the slurry and aggregate was already strong, resulting in insignificant contributions of pozzolanic reaction. Aggregate strength is the main influencing factor of mixture strength. Nevertheless, magnesium slag has low strength, and a high fine slag content is observed in the mixture, resulting in poor stability and easy damages by loads. Hence, the growth rate of compressive strength significantly decreased.

Fig. 2 shows that the unconfined compressive strength of the mixture continued to increase throughout the entire curing periods with the increase in magnesium slag content. The growth amplitude of compressive strength when magnesium slag content increased from $60 \%$ to $80 \%$ significantly decreased compared with that when magnesium slag content increased from $40 \%$ to $60 \%$. This finding indicates that excessive high magnesium slag content can restrict the growth amplitude of strength. Thus, the interlocking among mixture aggregates was enhanced by increasing magnesium slag content due to a low magnesium slag content. Meanwhile, the internal gel content in the mixture and the compressive strength of the mixture significantly increased. The activity of magnesium slag is partially excited due to the high magnesium slag content. Moreover, magnesium slag has minimal strength, and the crushing rate is relatively high in the compaction moulding process, thus decreasing its contribution to the overall structure. Li et al. (2017) pointed out in the study that for the mechanical properties of cement stabilized material base, the defects of low aggregate strength can be compensated by increasing the amount of cement appropriately. Therefore, the growth amplitude of strength was relatively small when the magnesium slag content was relatively high. The compressive strength of the mixture was increased by rising cement content under this circumstance.

Fig. 3 shows that the unconfined compressive strength of the mixture in different curing periods increases with the cement content. Compared with the $7 \mathrm{~d}$ unconfined compressive strength of the 3-B group, that of the 5-B and 7-B groups respectively increased by $73.2 \%$ and $164.6 \%$, and the $90 \mathrm{~d}$ 
unconfined compressive strength respectively increased by $22.6 \%$ and $76.7 \%$. Overall, increasing the cement content can significantly influence the mechanical properties in the early stage. This is consistent with the study of $\mathrm{Ji}$ et al. In early maintenance, cement hydration plays a leading role which producing more hydration products to make a denser structure (Ji et al., 2020).

The most common cement content is approximately $5 \%$ in practical engineering. The test results show that the calculation formula of $7 \mathrm{~d}$ unconfined compressive strength of the mixture with different magnesium slag contents under $5 \%$ cement content is as follows:

$$
R_{7 d}=\ln (-44.331+127.143 x), R^{2}=0.964,
$$

where $R_{7 d}$ is the $7 \mathrm{~d}$ unconfined compressive strength [MPa], $x$ is the magnesium slag content, and $R^{2}$ is the decisive coefficient.

Overall, the variation trends of compressive strength of mixtures with the increase in curing period and cement content conform to the characteristics of the cement-stabilized base (Hu \& Sha, 2012; Jiang, 2018; Karatag, Firat \& Isik, 2020). The regulations of Specification for Design of Highway Asphalt Pavement (JTG D50-2017) indicate that the $7 \mathrm{~d}$ strength of cement-stabilized materials must reach 2.0 4.0, 3.0-5.0, and 4.0-6.0 MPa when respectively used in moderate/light, heavy, and extremely heavy and ultra-heavy traffic asphalt pavement base of highways. Eq. 8 and the test results reveal that the magnesium slag content should be higher than $45 \%$ under $5 \%$ cement content to meet the lowest strength requirement of the pavement base. Only 5-A applies to the subbase; thus, the four remaining groups can all be used as pavement bases of different grades of highways. The 7d strength of 7-B has meets the strength requirements of extremely heavy and ultraheavy bases of highway and level-1 highway. Therefore, using cement-stabilized magnesium slag-Aeolian sand mixture in the pavement base and subbase under various traffic conditions is feasible and has relatively good mechanical properties.

\section{GRA of Influencing Factors of Unconfined Compressive Strength}

The unconfined compressive strength of cement-stabilized magnesium slag-Aeolian sand mixtures is related to cement content, magnesium slag content, curing period, and water content, and their influencing degrees vary. Different factors have varying physical significances. Thus, the data dimensions vary, which complicates direct comparison and acquisition of accurate conclusions from comparison. Hence, GRA was applied for quantitative analysis in the present study, and the main influencing factors were determined. The obtained results can provide references to the design and construction of the cement-stabilized magnesium slag-Aeolian sand mixture.

Tab. 10 shows the test results of unconfined compressive strength. The unconfined compressive strength $(Y)$ was used as the reference sequence, while cement content $\left(X_{1}\right)$, magnesium slag content ( $\left.X_{2}\right)$, curing period $\left(X_{3}\right)$, and water content $\left(X_{4}\right)$ were used as the comparison sequence. The numerical values in Tab. 10 were initialized, and the difference sequence was calculated to obtain the grey relational coefficient. Tab. 11 shows the results.

Tab. 10. Unconfined compressive strength of cement-stabilized magnesium slag-Aeolian sand

\begin{tabular}{ccccccccccccccccccccccccc}
\hline$Y \quad[\mathrm{MPa}]$ & 1.76 & 1.39 & 3.44 & 3.58 & 4.51 & 2.09 & 1.86 & 3.62 & 3.91 & 5.52 & 3.76 & 3.34 & 5.14 & 5.53 & 7.13 & 4.77 & 4.42 & 6.28 & 6.75 & 8.43 \\
\hline$X_{2}[\%]$ & 3 & 5 & 5 & 5 & 7 & 3 & 5 & 5 & 5 & 7 & 3 & 5 & 5 & 5 & 7 & 3 & 5 & 5 & 5 & 7 \\
$X_{2}[\%]$ & 60 & 40 & 60 & 80 & 60 & 60 & 40 & 60 & 80 & 60 & 60 & 40 & 60 & 80 & 60 & 60 & 40 & 60 & 80 & 60 \\
$X_{3}[\mathrm{~d}]$ & 3 & 3 & 3 & 3 & 3 & 7 & 7 & 7 & 7 & 7 & 28 & 28 & 28 & 28 & 28 & 90 & 90 & 90 & 90 & 90 \\
$X_{4}[\%]$ & 9.5 & 9.9 & 10.4 & 11.1 & 10.6 & 9.5 & 9.9 & 10.4 & 11.1 & 10.6 & 9.5 & 9.9 & 10.4 & 11.1 & 10.6 & 9.5 & 9.9 & 10.4 & 11.1 & 10.6 \\
\hline
\end{tabular}

Tab. 11. Calculated results of relational coefficient

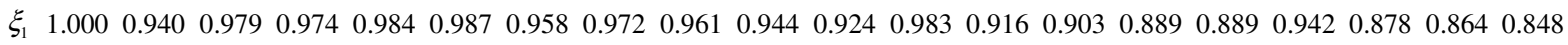

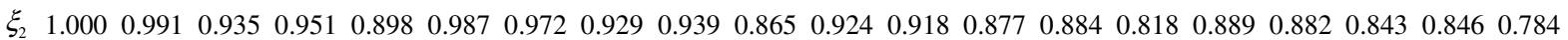

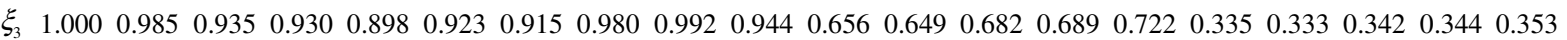

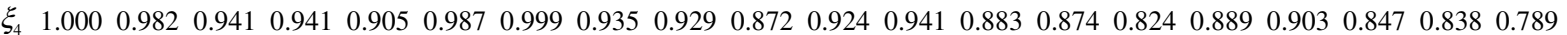


Finally, the grey relational degree was calculated.

$\gamma_{1}=0.9368$ (Relational degree between cement content and unconfined compressive strength)

$\gamma_{2}=0.9066$ (Relational degree between magnesium slag content and unconfined compressive strength)

$\gamma_{3}=0.7305$ (Relational degree between curing period and unconfined compressive strength)

$\gamma_{4}=0.9101$ (Relational degree between water content and unconfined compressive strength)

The corresponding sequence of relational degrees was $\gamma_{1}>\gamma_{4}>\gamma_{2}>\gamma_{4}$. A factor with a high relational degree is important (Mondal \& Pramanik, 2015; Balamurugan, 2020). The results demonstrated that cement content mostly influences the unconfined compressive strength of cementstabilized magnesium slag-Aeolian sand mixtures, followed by water content, magnesium slag content, and curing period successively.

Combined with the research results of unconfined compressive strength, choosing the appropriate cement content first in practical engineering applications and then determining the mixing ratio for production considering magnesium slag content and grade of highways is suggested to meet the strength requirements of bases. Magnesium slag content cannot significantly influence the compressive strength of mixtures when the magnesium slag content is higher than $80 \%$. Hence, cement content should be increased to adapt to the base of high grades of highways. Meanwhile, the water content can significantly influence the compressive strength of cement-stabilized magnesium slag-Aeolian sand mixture. In practical engineering use, water content should be increased appropriately during mixing, wetting before compacting, and watering during curing to assure the normal strength formation of the cement-stabilized magnesium slag-Aeolian sand base.

\section{Splitting Strength}

The test results of splitting strength of mixtures into different curing periods under 5\% cement content and magnesium slag content are different, as shown in Fig. 4. The test results of splitting strength of mixtures into different curing periods under $60 \%$ magnesium slag content and cement content are also different, as shown in Fig. 5. The relation between splitting strength $\left(S_{t}\right)$ and curing period $(t)$ was fit. Figs. 4 and 5 show the fitting result models.
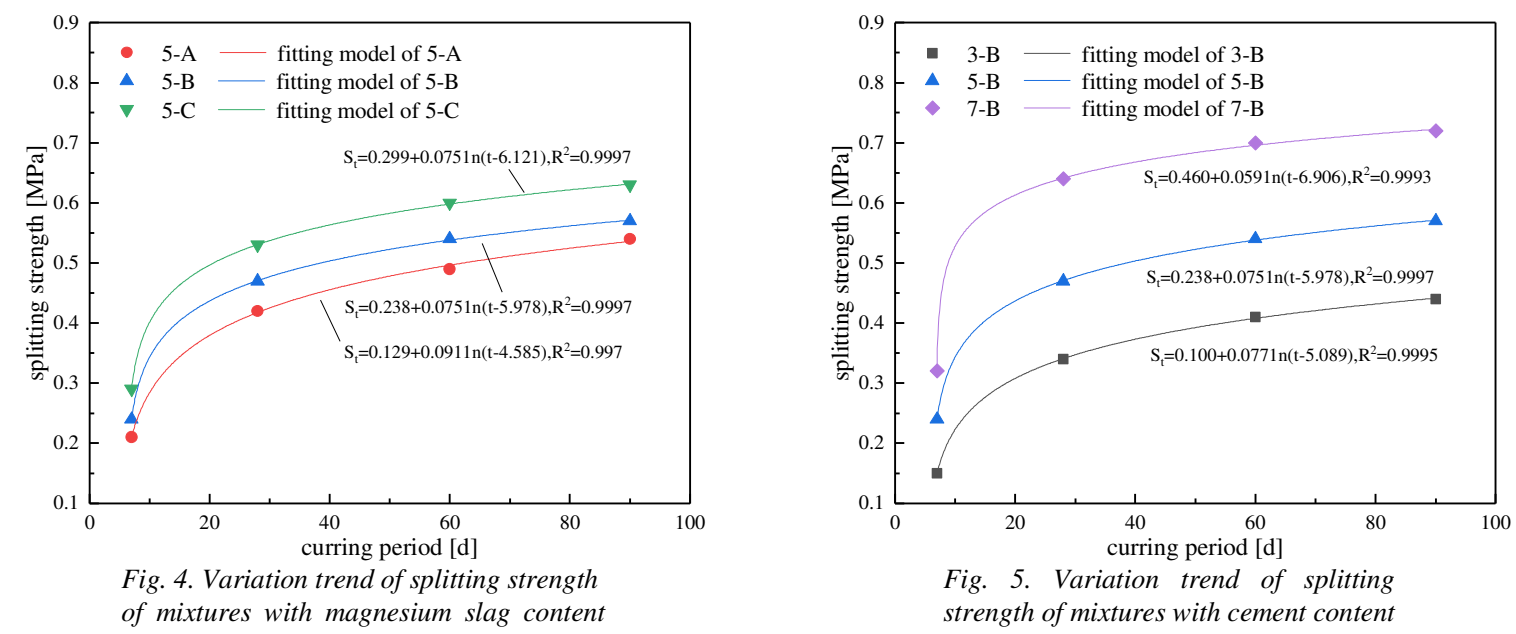

Figs. 4 and 5 show a logarithmic relationship between splitting strength and curing period. Therefore, splitting strength continued to increase with the curing period, and the growth amplitude gradually decreased. The splitting strength of mixtures in different curing periods increased by $38.1 \%$, $26.1 \%, 22.4 \%$, and $16.7 \%$ when magnesium slag content increased from $40 \%$ to $80 \%$ under $5 \%$ of cement content. The splitting strength of mixtures in different curing periods increased by $113.3 \%$, $88.2 \%, 70.7 \%$, and $63.6 \%$ when the cement content increased from $3 \%$ to $7 \%$ under $60 \%$ magnesium slag content. Thus, splitting strength was positively related to magnesium slag and cement contents. However, the influences of magnesium slag and cement contents on splitting strength were weakened in the late curing period. 
Magnesium slag content influences splitting strength less than unconfined compressive strength. This trend is consistent with the test results reported by Xiao et al. (2020). The reasons are introduced as follows. In addition to aggregate strength, the cohesive force of the mixture can significantly influence splitting strength. The mixture was moulded and mainly comprised three parts after a certain curing period, namely set cement, aggregate, and set cement-aggregate transition zone. The splitting failure mode of specimens was close to the tensile failure. Most failures initially occurred in the transition zone with the stretching of the cement-stabilized mixture. Hence, strength at the transition zone can significantly influence splitting strength (Hu \& Sha, 2012). The absorbed water is beneficial for cement hydration due to the high water absorption of magnesium slag. Additional gels are formed on the magnesium slag-Aeolian sand-cement interface due to magnesium slag activity to increase the strength of the transition zone. In addition, the fine aggregate of the mixture is reduced, and the specific surface area decreases with the increase in magnesium slag content, thus raising the amount of cement mortar wrapped on the aggregate surface. Combined with the above factors, the mixture possesses high splitting strength. During the splitting test of cement stabilized materials, the splitting failure first occurs in the weak area of the mixture (Zhou, Zhang \& Du, 2020). Magnesium slag has lower strength compared with the transition zone and becomes a weak part of the mixture. Some cracks initiate from inside of coarse magnesium slags in the splitting strength test (Fig. 6). Therefore, the cohesive force of the mixture can be significantly increased by raising magnesium slag content. However, one part of such impact is offset by the splitting of magnesium slags. Hence, magnesium slag content influences splitting strength less than unconfined compressive strength.
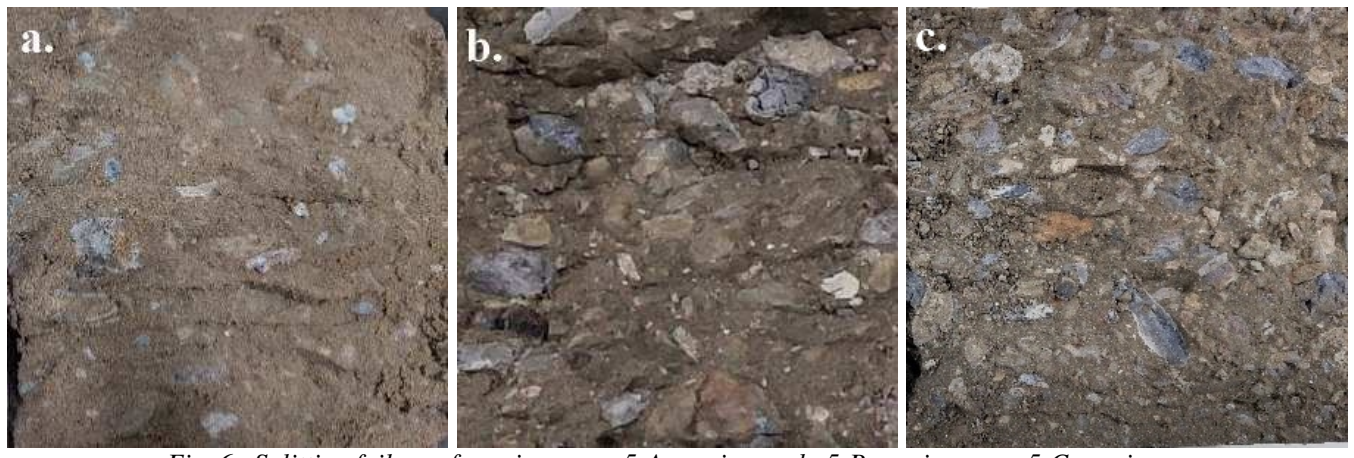

Fig. 6. Splitting failure of specimens: $a$. 5-A specimens, $b$. 5-B specimens, $c$. 5-C specimens

\section{Compressive Modulus of Resilience}

The modulus of resilience of the semi-rigid base is an important parameter of the entire pavement design. This parameter can reflect difficulties in the elastic deformation of materials and characterize material rigidity. Figs. 7 and 8 show the test results of compressive modulus of mixture resilience in different curing periods under 5\% cement content and magnesium slag contents and those in different curing periods under $60 \%$ magnesium slag and cement contents.

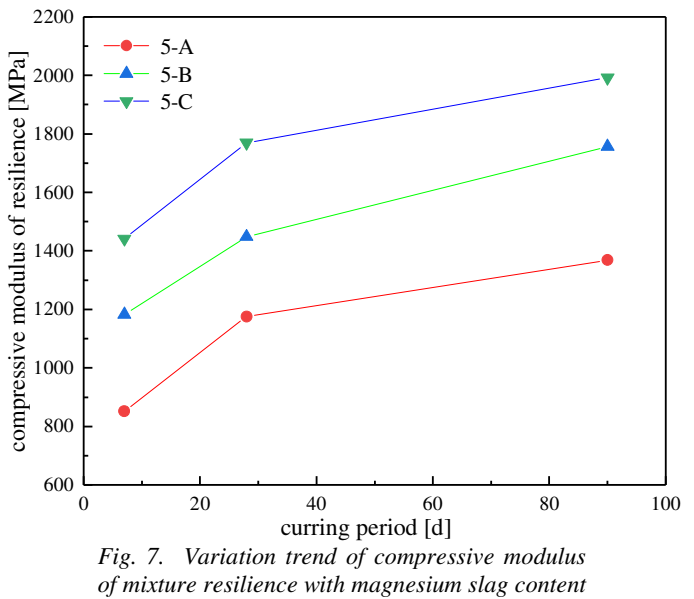

of mixture resilience with magnesium slag content

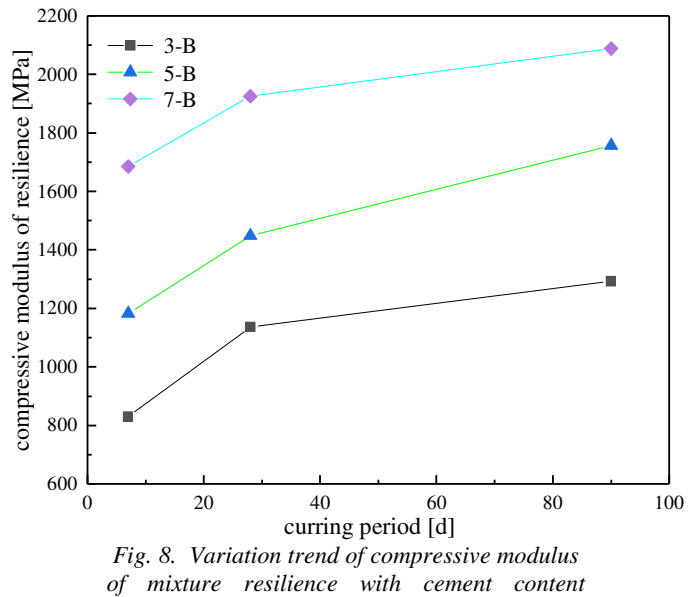

of mixture resilience with cement content 
Figs. 7 and 8 reveal that the compressive modulus of resilience of the mixture quickly increased in the early stage, but the growth trend decreased in the late stage. The variation laws of compressive modulus of resilience are similar to those of unconfined compressive strength. Moreover, the strength comparison of different specimens showed that the compressive modulus of resilience of mixtures continued to increase with the magnesium slag and cement contents in different curing periods. The compressive modulus of resilience (mean of $7 \mathrm{~d}, 28 \mathrm{~d}$, and 90d, hereinafter the same) of 5-B and 5-C groups were respectively increased by $30.1 \%$ and $54.9 \%$ compared with that of the 5-A group. The compressive modulus of resilience of the 5-B and 7-B groups respectively increased by $35.2 \%$ and $77.9 \%$ compared with that of the 3-B group. Bahmani et al. found that hydration products can increase the density and stiffness of the material and increase the strength of the mixture (2016). Similarly, raising the magnesium slag and cement contents can increase the hydration products and enhance the stiffness of the mix, which makes the mix has high resistance to deformation. This is consistent with the case of mechanical strength. The mixture can be viewed as a multiphase body comprising set cement and magnesium slag-Aeolian sand. The compressive modulus of resilience of the mixture is related to the aggregate properties and the transition zone characteristics. With the increase in magnesium slag and cement contents, additional gels can be produced in the transition zone due to cement hydration and pozzolanic reaction and hydration of magnesium slags, thus significantly increasing rigidity. Moreover, magnesium slag is porous, and gels mix with fine aggregates of Aeolian sands and penetrate magnesium slags to form strong integrity. Thus, the elasticity modulus of magnesium slags is strengthened, and the overall rigidity of the mixture is improved to some extent.

The maximum tension stress that occurs at the bottom of the base course rise significantly with the increased compressive modulus of resilience, so strength and modulus should match each other (Ren, Wang \& Zang, 2020). Test data of unconfined compressive strength and modulus of resilience of different groups were drawn into a diagram (Fig. 9).

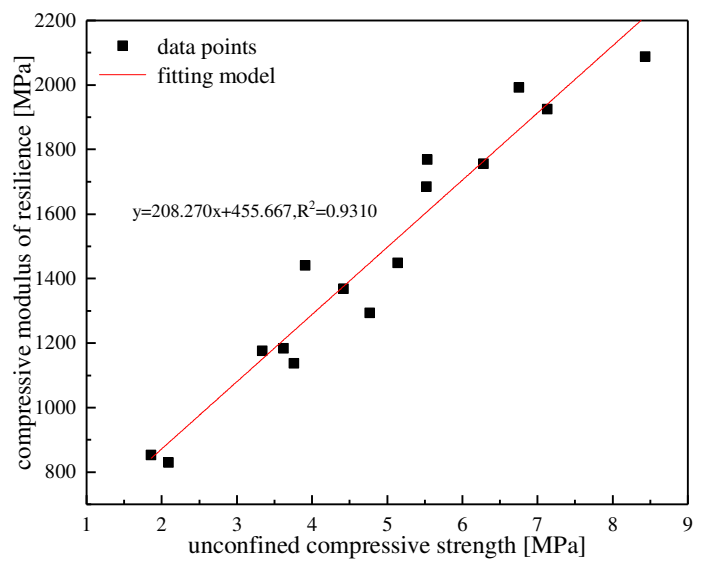

Fig. 9. Relationship between unconfined compressive strength and modulus of resilience

The relation formula between unconfined compressive strength and modulus of resilience of mixtures was fit according to Fig. 9.

$$
y=208.270 x+455.667, R^{2}=0.9310,
$$

where $y$ is the compressive modulus of resilience [MPa], $x$ is the unconfined compressive strength [MPa], and $R^{2}$ is the decisive coefficient.

Eq. 9 shows a good linear correlation between the compressive modulus of resilience and the strength of different specimen groups. This correlation reflects that the compressive strength of mixtures influences the compressive modulus of resilience to some extent. This finding explains the similar influence trend of different factors on the compressive modulus of resilience of the mixture to that of compressive strength. This trend is consistent with the results reported by Li et al. (2019). 


\section{Water Stability}

Among natural factors, water is the primary influencing factor of roads (Tarrago-Garay, RoyoAbancens \& Torreira-de-la-Hera, 2020). In particular, pavement base materials not only shall have sufficient strength but also maintain strength within the allowable range to sustain the normal working state of the pavement in the long-term water immersion environment (Li \& Shen, 2019). Hence, studying water stability is crucial to pavement construction. A water stability test of five groups was conducted in this study to evaluate the water stability capacity of cement-stabilized magnesium slag-Aeolian sand mixture and calculate the strength variation rate. Tab. 12 shows the results of this test.

\begin{tabular}{cccc}
\multicolumn{5}{c}{ Tab. 12. Test results of water stability } \\
\hline $\begin{array}{c}\text { Testing } \\
\text { groups }\end{array}$ & $\begin{array}{r}\text { 28 d unconfined compressive } \\
\text { strength [MPa] }\end{array}$ & $\begin{array}{c}\text { 7 d unconfined compressive strength after water } \\
\text { immersion [MPa] }\end{array}$ & $\begin{array}{c}\text { Strength variation rate } \\
{[\%]}\end{array}$ \\
\hline 3-B & 3.72 & 3.77 & 1.34 \\
5-A & 3.34 & 3.40 & 1.80 \\
5-B & 5.12 & 5.23 & 2.15 \\
5-C & 5.34 & 5.54 & 3.75 \\
7-B & 7.10 & 7.38 & 3.94 \\
\hline
\end{tabular}

Tab. 12 shows that compared with standard curing, the unconfined compressive strengths of all specimens after immersion in water for $7 \mathrm{~d}$ all increased, indicating the good water stability of mixtures. Compressive strength increases with the curing period under the water immersion state but is lower than the growth amplitude of strength under standard curing conditions.

The strength variation rate of the mixture increases from $1.34 \%$ to $3.94 \%$ as cement content rises from $3 \%$ to $7 \%$, indicating the positive effects of cement content on water stability. Moreover, the strength variation rate increases with the magnesium slag content. Despite compacted mixture, pore size reduction, and increased difficulties for water penetration in specimens due to increasing fine aggregate content (Shang, 2019), the magnesium slag produces gels through hydration, which bond and harden with Aeolian sands into stone structures. These products can effectively prevent water entrance into particles. Hence, increasing magnesium slag content can significantly improve water stability.

\section{Pavement of the Testing Section}

A testing section of $100 \mathrm{~m}$ long and $8 \mathrm{~m}$ wide cement-stabilized magnesium slag-Aeolian sand base and subbase was paved near the Xiadujia Huopan, Laogaochuan Town by combining the rebuilding highway of Yeda Road, Fugu County, Yulin City, China to verify the road performances of cementstabilized magnesium slag-Aeolian sand base. Tab. 13 shows the pavement structure. The mass ratio between magnesium slag and Aeolian sand in the base and subbase was set to 60:40, while cement content was $5 \%$ and $4 \%$. The technological indexes of $\mathrm{P} \cdot \mathrm{O} 42.5 \mathrm{H}$ cement, magnesium slag, and Aeolian sand, which were used in the testing section, are listed in Tabs. 1, 3, 4, and 6. The base was constructed in accordance with the requirements of JTG/T F20-2015, and water use was appropriately increased in mixing, wetting before grinding and curing processes. Four times of vibrating compactions were performed by a heavy road roller. The field compaction degree was tested by the sand cone method, which met the design requirements.

Tab. 13. Pavement structure of testing section

\begin{tabular}{cr} 
& Tab. 13. Pavement structure of testing section \\
\hline Upper surface & $5 \mathrm{~cm}$ thick bituminous concrete \\
\hline Lower surface & $7 \mathrm{~cm}$ thick bituminous concrete \\
Upper base & $16 \mathrm{~cm}$ thick $5 \%$ cement-stabilized magnesium slag-Aeolian sand \\
Lower base & $16 \mathrm{~cm}$ thick $5 \%$ cement-stabilized magnesium slag-Aeolian sand \\
Subbase & $20 \mathrm{~cm}$ thick $4 \%$ cement-stabilized magnesium slag-Aeolian sand \\
\hline
\end{tabular}

Core samples were collected from the testing section through the drilling sampling method at $7 \mathrm{~d}$ of the curing period (Fig. 10). The $7 \mathrm{~d}$ unconfined compressive strengths of base and subbase were 3.57 and 2.93 MPa, respectively. These values met the standard requirements, in which compressive strengths 
of base and foundation should respectively be $\geqslant 3.0$ and $\geqslant 2.0 \mathrm{MPa}$ under level-2 highway heavy traffic conditions. Fig. 11 shows the situation of the testing section after opening to traffic for half a year. This result indicates that the testing section showed good overall service performance without cracks and settlements. Thus, using cement-stabilized magnesium slag-Aeolian sand mixture as the pavement base and subbase is feasible and has good strength and stability.

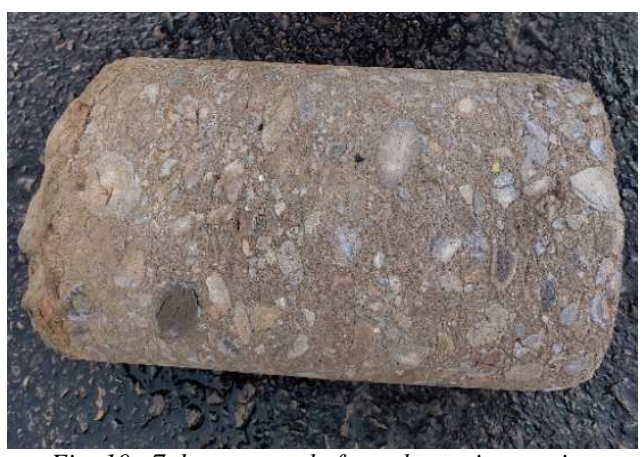

Fig. 10. 7 d core sample from the testing section

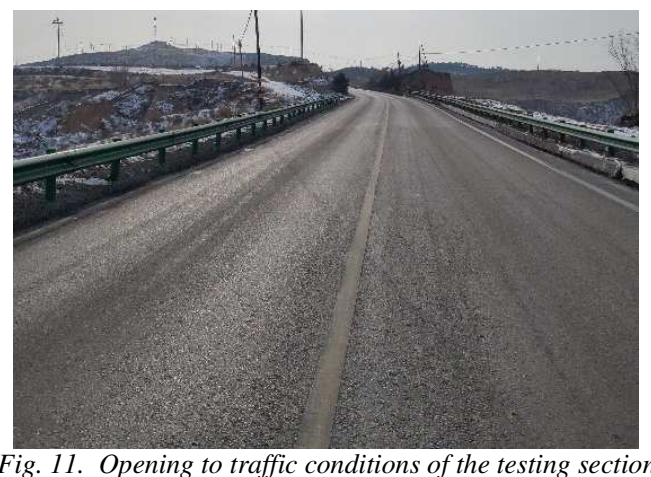

Fig. 11. Opening to traffic conditions of the testing section

\section{Conclusions}

This study chooses the optimized magnesium slag and Aeolian sand as the research objects to explore the feasibility of using cement-stabilized magnesium slag-Aeolian sand as the pavement base. The basic performances of these research objects are tested. The performances of cement-stabilized magnesium slag-Aeolian sand mixture under different cement contents, magnesium slag contents, and curing periods are discussed through various laboratory tests and the GRA method. Moreover, a testing section is paved. Finally, some major conclusions could be drawn as follows.

Magnesium slag has a high crushing value, water absorption, and active matter content. Aeolian sand is a kind of ultrafine sand with good continuity and easy compaction. The mixture with high magnesium slag content has a small maximum dry density and high optimal water content.

Compressive strength increases with the magnesium slag content. The growth amplitude is small when the magnesium slag content is relatively high. The variation trends of compressive strength with curing period and cement content conform to the characteristics of the cement-stabilized base. Among different influencing factors, cement content mostly influences the unconfined compressive strength, followed by water content, magnesium slag content, and curing period successively.

Splitting strength and compressive modulus of resilience are positively related to cement and magnesium slag contents. Moreover, magnesium slag content influences splitting strength less than unconfined compressive strength. The mixture has good water stability, and increasing cement and magnesium slag contents positively affect water stability.

The testing section proved that the bituminous pavement with cement-stabilized magnesium slagAeolian sand base and subbase has good performances, and using cement-stabilized magnesium slagAeolian sand mixture as the base and subbase materials is feasible.

Combining with research results, the mixture, which has magnesium slag content higher than $45 \%$ under the 5\% 42.5 normal Portland cement and overall blending conditions, can be used as asphalt pavement base of different grades of highways. The cement content should be increased to improve the strength of the mixture base when the magnesium slag content is higher than $80 \%$. The mixture can be used as the pavement subbase when the magnesium slag and Aeolian sand contents are $40 \%$ and $60 \%$, respectively.

Overall, the proposed cement-stabilized magnesium slag-Aeolian sand mixture can effectively solve practical problems, which conforms to the basic principle of turning waste into wealth and using local materials. Moreover, the mixture has good usability, and the testing section shows good conditions. This study establishes the foundation for the promotion and application of industrial slags (e.g., magnesium slags) and Aeolian sand. However, mixtures have complicated compositions. Thus, this study did not comprehensively investigate the influencing factors of the performances of cementstabilized magnesium slag-Aeolian sand mixture. Moreover, this study has some limitations. Hence, future studies can use microscopic technology to analyze the strength formation mechanism of mixtures 
and add drying temperature shrinkage and anti-frost performance tests. These results can provide references to the promotion of cement-stabilized magnesium slag-Aeolian sand base.

\section{References}

Amini, O., \& Ghasemi, M. (2019). Laboratory study of the effects of using magnesium slag on the geotechnical properties of cement stabilized soil. Construction and Building Materials, 223, 409-420. https://doi.org/10.1016/j.conbuildmat.2019.07.011

Balamurugan, S. (2020). Application of Multi-Attribute Decision Making Approach for Transesterification Process using Grey Relational Analysis. Journal of Engineering Science \& Technology Review, 13(4), 214218. https://doi.org/10.25103/jestr.134.21

Barišić, I., Dimter, S., \& Rukavina, T. (2013). Strength properties of steel slag stabilized mixes. Composites Part B: Engineering, 58, 386-391. https://doi.org/10.1016/j.compositesb.2013.11.002

Bahmani, S., Farzadnia, N., Asadi, A., \& Huat, B. (2016). The effect of size and replacement content of nanosilica on strength development of cement treated residual soil. Construction and Building Materials, 118, 294306. https://doi.org/10.1016/j.conbuildmat.2016.05.075

Djokic, J., Minic, D., \& Kamberovic, Z. (2012). Reuse of metallurgical slag from the silicothermic magnesium production and secondary lead metallurgy. Metalurgia International, 17(3), 46-52.

Du, Q., Cui, Z., Zhao, W., Du, F., \& Li, H. (2010). Experimental study on performance of magnesium slagmodified asphalt. New Building Materials, 37(2), 58-60+74. https://doi.org/10.3969/j.issn.1001$702 X .2010 .02 .016$

Ge, X., Ge, Z., \& Yang, W. (2005). Characteristic of eolian sand and application in road construction. Journal of Liaoning Technical University, 24(3), 372-374. https://doi.org/10.3969/j.issn.1008-0562.2005.03.021

Guo, G., Zhang, Y., \& Du, S. (2017). Grassroots-level Shear Strength Experimental Study of Aeolian Sand with Cement. Science Technology and Engineering, 17(15), 322-326. https://doi.org/10.3969/j.issn.16711815.2017.15.053

Hu, L., \& Sha, A. (2012). Performance test of cement stabilized crushed clay brick for road base material. China Journal of Highway and Transport, 25(3), 73-79. https://doi.org/10.19721/j.cnki.1001-7372.2012.03.006

Ji, Y., Li, Y., Yang, K., \& Wu, Y. (2017). Properties of quenching magnesium slag cement cementitious materials. Journal of Xi'an University of Architecture \& Technology: Natural Science Edition, 49(2), 277-283. https://doi.org/10.15986/j.1006-7930.2017.02.029

Jiang, W. (2018). Research on the strength mechanism of inorganic binder iron tailings and the optimization design application to the base layer. M.A Thesis, Harbin Institute of Technology.

Ji, G., Peng, X., Wang, S., Hu, C., Ran, P., Sun, K., \& Zeng, L. (2021). Influence of magnesium slag as a mineral admixture on the performance of concrete. Construction and Building Materials, 295, 123619. https://doi.org/10.1016/j.conbuildmat.2021.123619

Karatag, H., Firat, S., \& Isik, N. S. (2020). Utilization of steel slag as road base and subbase material. Journal of Polytechnic, 23(3), 799-812.

Kumar, A., Kumar, S., \& Mukhopadhyay, N. K. (2018). Introduction to magnesium alloy processing technology and development of low-cost stir casting process for magnesium alloy and its composites. Journal of Magnesium and Alloys, 6(3), 245-254. https://doi.org/10.1016/j.jma.2018.05.006

Li, W., Lang, L., Lin, Z., Wang, Z., \& Zhang, F. (2017). Characteristics of dry shrinkage and temperature shrinkage of cement-stabilized steel slag. Construction and Building Materials, 134, 540-548. https://doi.org/10.1016/j.conbuildmat.2016.12.214

Liu, L., Ruan, S., Qi, C., Zhang, B., \& Song, I. (2020). Co-disposal of magnesium slag and high-calcium fly ash as cementitious materials in backfill. Journal of Cleaner Production, 279(2), 123684. https://doi.org/10.1016/j.jclepro.2020.123684

Liu, Q., Ma, J., \& Zheng, W. (2019). Study on the Effect of Ash-Slag Ratio on Mechanical Properties of Magnesium Slag Cementitious Material. IOP Conference Series: Earth and Environmental Science, 371(4), 042036.

Lopez-Querol, S., Arias-Trujillo, J., Maria, G. E., Matias-Sanchez, A., \& Cantero, B. (2017). Improvement of the bearing capacity of confined and unconfined cement-stabilized aeolian sand. Construction and Building Materials, 153, 374-384. https://doi.org/10.1016/j.conbuildmat.2017.07.124

Li, W., Wei, H., Wang, Z., Li, Y., \& Feng, X. (2019). Pavement performance of a regenerated cement stabilized mixture on construction waste. Journal of Chang'an University: Natural Science Edition, 39(4), 52-61. https://doi.org/10.19721/j.cnki.1671-8879.2019.04.007

Li, Z., \& Shen, X. (2019). Experimental study on cement-based stabilized phosphogypsum modified by sodium silicate in pavement base. Journal of Engineering Geology, 27(1), 80-87. https://doi.org/ 10.13544/j.cnki.jeg.2019-012 
Maghool, F., Arulrajah, A., Du, Y. J., Horpibulsuk, S., \& Chinkulkijniwat, A. (2017). Environmental impacts of utilizing waste steel slag aggregates as recycled road construction materials. Clean Technologies and Environmental Policy, 19(4), 949-958. https://doi.org/10.1007/s10098-016-1289-6

Mao, X. (2017). Application of non-ferrous metal smelting slag in urban road base material. M.A Thesis, Dalian Jiaotong University.

Martinez-Sentana, A., Valero-Verdu, S., \& Senabre-Blanes, C. (2020). Energy sustainability: Macroeconomic indicators and productive sectors. DYNA, 95(2), 139-143. https://doi.org/10.6036/9183

Mondal, K., \& Pramanik, S. (2015). Neutrosophic decision making model for clay-brick selection in construction field based on grey relational analysis. Neutrosophic Sets and Systems, 9, 64-71.

Osmani, F., Shabani, B., \& Ilazi, M. (2020). The Importance of SD Goals Indicators 7, 8, 9 and 12 in the Industry Development by Using Multi Criteria and Decision Making Method. Tehnički glasnik, 14(4), 524-530. https://doi.org/10.31803/tg-20200917084550

Phanikumar, B., \& Raju, E. (2020). Compaction and strength characteristics of an expansive clay stabilized with lime sludge and cement. Soils and Foundations, 60(1), 129-138. https://doi.org/10.1016/j.sandf.2020.01.007

Ren, J., Wang, S., \& Zang, G. (2020). Effects of recycled aggregate composition on the mechanical characteristics and material design of cement stabilized cold recycling mixtures using road milling materials. Construction and Building Materials, 244, 118329. https://doi.org/10.1016/j.conbuildmat.2020.118329

Shalabi, F. I., Mazher, J., Khan, K., Alsuliman, M., Almustafa, I., Mahmoud, W., \& Alomran, N. (2019). Cementstabilized waste sand as sustainable construction materials for foundations and highway roads. Materials, 12(4), 600. https://doi.org/10.3390/ma12040600

Shang, X. (2019). Research on Technical Performance of Cement Stabilized Construction Waste Pavement Base. M.A Thesis, Chang'an University.

Shen, H., \& Forssberg, E. (2003). An overview of recovery of metals from slags. Waste Management, 23(10), 933949. https://doi.org/10.1016/S0956-053X(02)00164-2

Solonenko, I. (2019). The use of cement concrete pavements for roads, depending on climatic conditions. Tehnički glasnik, 13(3), 235-240. https://doi.org/10.31803/tg-20190518181647

Song, L., \& Li, B. (2020). Effect of Aeolian Sand Content on Mechanical Properties and Durability of Cement Stabilized Graded Macadam. Bulletin of the Chinese Ceramic Society, 39(5), 1421-1429. https://doi.org/10.16552/j.cnki.issn1001-1625.2020.05.009

Singh, S., Tripathy, D., \& Ranjith, P. (2008). Performance evaluation of cement stabilized fly ash-GBFS mixes as a highway construction material. Waste Management, 28(8), 1331-1337. https://doi.org/10.1016/j.wasman.2007.09.017

Tarrago-Garay, N., Royo-Abancens, F. J., \& Torreira-de-la-Hera, I. (2020). Vulnerability of infrastructures to climate events. Road flooding. DYNA, 95(6), 661-667. https://doi.org/10.6036/9650

Xiao, L., Lu, F., Wang, S., Wang, S., Li, R., \& Wang, Y. (2011). Study of new magnesium slag energy-saving insulation wall material. New Building Materials, 38(7), 21-23. https://doi.org/10.3969/j.issn.1001702X.2011.07.007

Xiao, J., Wu, C., Zhan, Z., Tan, X., \& Dong, W. (2017). Research on performances of cement stabilized brick and concrete recycled aggregate base. China Journal of Highway and Transport, 30(2), 25-32. https://doi.org/10.19721/j.cnki.1001-7372.2017.02.004

Zhai, X., Cheng, Z., Chang, S., Ai, X., \& Zhang, X. (2020). An analysis on the current situation of energy development and its environmental problems in Yulin City. Energy Reports, 6, 15-20. https://doi.org/10.1016/j.egyr.2019.08.011

Zhang, H., Cheng, P., Shao, H., \& Wang, L. (2007). Test Research on Temperature Shrinkage Performance of Cement and Cinder Stabilized Coal Gangue Base Course Materials. Journal of Highway and Transportation Research and Development, 24(11), 29-32. https://doi.org/10.3969/j.issn.10020268.2007.11.007

Zhang, S., Li, Z., Peng, D., \& Chen, Z. (2007). Study of static property of aeolian sand used as roadbed. Rock and Soil Mechanics, 28(12), 2511-2516. https://doi.org/10.16285/j.rsm.2007.12.010

Zhang, X., \& Ren, K. (2018). Strength and damage characteristic of cement stabilized cinder macadam base. Journal of Traffic and Transportation Engineering, 18(6), 1-9. https://doi.org/10.19818/j.cnki.16711637.2018.06.001

Zhao, S., Han, F., \& Wang, Y. (2017). Preperation of Composite Slag Sulphoaluminate Cement Clinker from Electrolytic Manganese-Magnesium. Bulletin of the Chinese Ceramic Society, 36(5), 1766-1772+1776. https://doi.org/10.16552/j.cnki.issn1001-1625.2017.05.053

Zhou, F., Zhang, L., \& Du, Y. (2020). Mechanical Properties of Cement Stabilized Recycled Aggregates with Crushed Brick. Journal of Hunan University: Natural Sciences, 47(5), 134-140. https://doi.org/10.16339/j.cnki.hdxbzkb.2020.05.015 